\title{
Rectificación del humanismo
}

\section{Pedro Cerezo Galán'}

Pedro Cerezo Galán, maestro de filósofos, es catedrático emérito de Filosofía de la Universidad de Granada. Con una fecunda trayectoria en docencia e investigación, la obra del profesor Cerezo abarca desde sus tempranos estudios sobre Aristóteles y Heidegger y sus escritos sobre el pensamiento de la modernidad, en especial el idealismo alemán, hasta sus libros mayores sobre grandes figuras de la tradición hispana. Así, sus trabajos sobre Antonio Machado-Palabra en el tiempo-, José Ortega y Gasset -La voluntad de aventura- y Miguel de Unamuno -Las máscaras de lo trágico y Miguel de Unamuno. Ecce Homo: La existencia y la palabra-son hitos de obligada referencia para quien se adentre por los caminos de la filosofía española. De la misma manera, sus investigaciones sobre la literatura y el pensamiento del barroco o sobre los debates intelectuales que marcaron en España el complejo paso del siglo XIX al siglo XX -magistralmente expuestos en El mal del siglo-, son escritos que no pueden faltar en cualquier estudio sobre épocas tan cruciales de nuestra historia. La sensibilidad del profesor Cerezo, su capacidad para tejer con los más diversos hilos a la búsqueda de las claves que nos permitan comprender nuestro tiempo, explican la profundidad y la altura de su obra filosófica. A su pensamiento le acompaña una firme voluntad de compromiso cívico que empapa todas sus páginas y que se hace explícita en libros tales como los que llevan por título Ética pública: éthos civil o Democracia y virtudes cívicas. Es ese entrelazamiento de pasión filosófica y compromiso ciudadano el que encuentra en la tradición humanista el humus donde enraizar sus fructíferas creaciones. El profesor Cerezo ofrece una muestra de ello en la lúcida aproximación que hace a la obra de Jacques Maritain Humanismo integral, realzando sus aportaciones en torno a la persona y su dignidad, núcleo seminal de un humanismo que trataba de abrirse paso en medio de una trágica coyuntura europea, a la búsqueda de una salida que aportara luz más allá de las insuficiencias y excesos de una modernidad que se bloqueaba a sí misma. En las actuales circunstancias de España y en medio de una difícil situación en Europa, la aportación del profesor Cerezo y el legado de Maritain siguen siendo de indudable relevancia. El texto reproduce con pequeños cambios el de la conferencia pronunciada por el profesor Cerezo en la Universidad Internacional Menéndez Pelayo (UIMP) de Santander el 3 de septiembre de 1986, con ocasión del cincuenta aniversario de la publicación en francés de Humanismo integral (París 1936, Aubier). Era director de aquel curso "La dialéctica hombre y Estado: en el cincuentenario de la presencia de Jacques Maritain en la Magdalena" el profesor Joaquín Ruiz-Giménez Cortés y secretario del mismo el autor del estudio, Pedro Cerezo [Pablo Pérez Espigares].

${ }^{1}$ Universidad de Granada. 
Resumen: Este estudio relaciona la crisis del humanismo a mediados del siglo XX, contexto en que se pronunciaron las "Lecciones de Santander" (agosto 1934) que están en el origen de Humanisme intégral de Jacques Maritain (París 1936, Aubier), con otras reflexiones inmediatamente posteriores sobre el tema como la de Heidegger. La síntesis de Maritain, en continuidad con la tradición cristiana, especialmente el tomismo, al mismo tiempo que mostraba la vitalidad de éste, ofrece un ejemplo de la novedad y la capacidad de diálogo del filósofo francés con el pensamiento de su tiempo, en orden a la necesaria "rectificación" del humanismo. Éste estaba entonces abocado a la contradicción de una reducción sea subjetivista, sea totalitaria. La salvación del humanismo, debe llegar, afirmó Maritain, por su transformación integradora del teocentrismo constitutivo.

Una comprensión integral de lo humano permite reordenar las relaciones entre lo temporal y lo sacral, entre cristianismo y democracia, con tolerancia por respeto a la autonomía personal. Maritain rectificó tanto el humanismo secularista (antropocéntrico) como el trascendentalismo que pretendía la hegemonía de la Iglesia católica en la ciudad secular, ya que para el filósofo personalista el cristianismo se sitúa en otro plano: el de la inspiración y la motivación moral, desasistido de todo privilegio social o influjo político.

Palabras clave: Democracia, Heidegger, humanismo integral, Maritain, persona, secularidad, transcendencia.

Fecha de recepción: 18 de octubre de 2015.

\section{Rectification of humanism}

Abstract: This study links the crisis of humanism in the mid-twentieth century, context in which the "Lessons of Santander" (August 1934) which are the source of Humanisme intégral de Jacques Maritain (Paris 1936, Aubier), with other immediately following reflections on the subject as of Heidegger. The synthesis of Maritain, in continuity with itChristian tradition, especially Thomism, while showing the vitality of this, offers an example of novelty and capacity for dialogue of the French philosopher with the thought of his time, in order to the necessary "rectification" of the humanism.

\section{Rectification de l'humanisme}

Résumé: Cette étude relie la crise de I'humanisme au milieu du XXème siècle XX, Le contexte où les "leçons de Santander » ont été prononcées (août 1934) qui sont à l'origine del'Humanisme intégral de Jacques Maritain (Paris, 1936, Aubier), avec d'autres réflexions immédiates sur le thème, comme celle de Heidegger. La synthèse de Maritain, en continuité avec la tradition chrétienne, en particulier le thomisme, montrait en même temps la vitalité de celle-là, en offrant un exemple de la nouveauté et de la capacité de dialogue du philosophe Français avec la pensée de son temps, pour la nécessaire 
This was then doomed to be the contradiction of a subjectivist or totalitarian reduction. The salvation of the humanism, must come, said Maritain, by its integrative transformation, inclusive establishing theocentrism.

An understanding integral of the human rearranges the relationship between the temporal and the sacral, between Christianity and democracy, between tolerance and respect for personal autonomy. Maritain both rectified secularist humanism (anthropocentric) as transcendentalism that sought hegemony of the Catholic Church in the secular city, since to the personalist philosopher Christianity lies at another level: the inspiration and moral motivation, unassisted by all social privilege or political influence.

Keywords: Democracy, Heidegger, integral humanism, Maritain, person, secularity, Transcendence. «rectification» de l'humanisme qui alors était voué à une réduction soit subjective, soit totalitaire. Le salut de l'humanisme, doit venir, écrivait Maritain, par sa transformation intégratrice d'un théocentrisme. Une compréhension intégrale de l'être humain permet de réorganiser les relations entre le temporel et le sacrum, christianisme et démocratie, avec tolérance et respect de l'autonomie personnelle. Maritain rectifia I'humanisme laïque (anthropocentrique) $\mathrm{d}^{\prime}$ autant que le transcendantalisme qu'avait I'intention d'obtenir l'hégémonie de l'Eglise catholique dans ville séculaire, puisque pour le philosophe personnaliste le christianisme se trouve dans un autre plan, celui de l'inspiration et de la motivation morale, sans la prétention des privilèges sociales ou des influence politiques.

Mots clé: Démocratie, Heidegger, humanisme intégral, Maritain, personne, sécularité, Transcendance.

\section{Introducción}

En 1934, año aciago para España, casi en preludio de la Guerra Civil, por la que se desangró la II República entre la 'cruzada' religiosa y la 'revolución' comunista, como fueron llamadas por sus protagonistas, daba Jacques Maritain un famoso curso de verano, en el palacio de La Magdalena (Santander) cuyas lecciones fueron la primicia de lo que sería más tarde el libro Humanismo integral, un "clásico del pensamiento cristiano", como lo ha calificado Henry Bars, en que se establece una nueva relación entre el cristianismo, la filosofía y la política. Humanismo integral es, ante todo, una respuesta lúcida al doble reto del mundo moderno y del cristianismo, de parte de un pensador, que se había mantenido en un tenso y fecundo diálogo con la modernidad, a la par que iba madurando en él su experiencia espiritual de la fe. Representa el alumbramiento de una nueva posición espiritual, en la que el cristianismo, tras dos siglos de proscripción, pudiera convertirse en un 
fermento animador de la cultura. Téngase presente la fecha, 1934, un punto clave entre las dos guerras mundiales libradas en el corazón de Europa, la del 14 y la del 39, con dos totalitarismos instaurados, el marxista y el nacionalsocialismo, y un liberalismo claudicante, que a duras penas podía contenerlos. En este periodo de entreguerras, en que se asiste a la quiebra de los grandes ideales de la cultura europea, nace la meditación de Maritain sobre el humanismo, cuyo propósito es bien explícito:

El mundo nacido del Renacimiento y la Reforma está devastado desde aquella época por energías poderosas y a decir verdad monstruosas, donde error y verdad se mezclan estrechamente y se alimentan el uno al otro, verdades que mienten y mentiras que dicen la verdad. Es obligación del que ama la sabiduría intentar purificar estas producciones anormales y monstruosas y salvar las verdades que han hecho delirar ${ }^{2}$.

Es, pues, la suya, dicho sea sin exageraciones, una ardua empresa de "salvación" de la cultura moderna, semejante en todo punto a la que Tomás de Aquino, su guía mentor, había llevado a cabo en el siglo XIII, con el mundo antiguo e inspirada en los mismos principios. Pero es también, a la recíproca, una empresa de "encarnación" de la fe en la mentalidad y la eticidad de una época secular, con el testimonio de que el reino de Dios quiere inhabitar el mundo. No hay que extrañarse si tal empresa fue mal comprendida en su tiempo. Unos se apresuraron a ver en ella el retorno de un sobrenaturalismo, que ya estaba desahuciado por la historia y la cultura. Otros, por el contrario, una recaída en el naturalismo del siglo, por pérdida de la diferencia esencial, que supone la fe. En verdad, el mensaje de Maritain era demasiado exigente para una cristiandad acomplejada y refugiada en la Iglesia como un gheto, y una secularidad demasiado orgullosa de sus conquistas. En 1934 su propuesta tenía un carácter desafiante y provocador para los beatos de uno $u$ otro signo, dedicados celosamente al cultivo del dogma de su heredad. Pero su intransigencia era de otro cariz; consistió en no resignarse a los planteamientos inertes heredados, a la doble verdad y a la esquizofrenia personal, y atreverse a explorar una nueva síntesis espiritual. A mi entender, este libro de Maritain fue precursor del espíritu del Vaticano Il en su búsqueda de una postura dialógica y comprometida con el mundo moderno, sin concesiones tácticas ni acomodaciones ideológicas, pero también sin miedo ni arrogancia doctrinal. Humanismo integral recoge esta propuesta en su doble vertiente teórico/práctica: ofrece, de un lado, la conjunción de la fe con la forma autónoma y secular, humanista, en una palabra, de la cultura moderna, recordando la herencia cristiana que subyace al humanis-

\footnotetext{
${ }^{2}$ Todos los textos son traducción del autor del artículo. Humanisme intégral, Paris 1947, Aubier, 7. En lo sucesivo será citado por la sigla HI, con una referencia a la edición de 1947 y otra a las Oeuvres complètes de Jacques y Raïssa MARITAIN 6 (1984), 295.
} 
mo liberal o al humanismo socialista, $y$, a la vez, encarando la posibilidad de un nueva cristiandad. En medio de la confusión y desorientación dominante en el siglo, sería para los cristianos una ocasión gallarda la de volver a llevar las cosas a la verdad, reintegrando en la plenitud de su fuente original estas esperanzas de justicia y estas nostalgias de comunión, cuyo pasto es el sufrimiento del mundo y cuyo ímpetu está desorientado, suscitando así una fuerza cultural y temporal de inspiración cristiana capaz de actuar sobre la historia y de ayudar a los hombres.

Una sana filosofía social y una sana filosofía de la historia les serían necesarias para ello. Trabajarían entonces en sustituir su régimen inhumano que agoniza bajo nuestros ojos en un nuevo régimen de civilización, que se caracterizaría por un humanismo integral, y que representaría a sus ojos una nueva cristiandad, no más sacral, sino secular o profana $(\mathrm{HI}, 14-15 ; 6,302-303)$.

Es preciso despejar un posible equívoco, que pudiera suscitar este título. Lo que significa Maritain con el calificativo "integral" no es una composición de los humanismos seculares, completándolos con determinados aspectos, que les hubieran quedado extraños, o intentando abrirlos a algo que hubieran olvidado. El calificativo "integral" es aquí determinante, hasta el punto de que sólo si es integral es una verdadero humanismo. Maritain está muy lejos de ser un pensador acomodaticio. Todo lo contrario; siempre reclama una actitud metafísica y ética, como base del pensamiento. Toda la sustantividad del nuevo humanismo reside precisamente en que sea una posición integral del hombre, y, sólo en esta medida, integradora de aquellas verdades y valores que se han ido promoviendo históricamente por las diversas tipos de humanismo. Y para alcanzar una forma integral tiene que afrontar el tema del hombre en su radicalidad ontológica. La categoría de persona es aquí, como se verá, la clave de sustentación. Sólo un humanismo de la persona, -no del mero individuo o de la mera colectividad humana-puede ser integral, porque alcanza aquel centro originario en el que el hombre está abierto a la totalidad del ser, al otro y a la otro de sí, en una palabra, a la Transcendencia. La salvación del humanismo tiene que llevarse a cabo mediante su transformación. Si se renuncia al concepto de personas de filiación cristiana, a aquello que por ser criatura de libertad es más que naturaleza, pero menos que espíritu soberano, ya no seria posible la integridad del humanismo. A los ojos de Maritain, lo deficiente del humanismo moderno está en su falta de radicalidad ontológica, y, por tanto, de sentido religioso de la profundidad del ser. Se trata de un humanismo plano, reductivo, que no puede abrirse al todo del ser porque comienza encerrando al hombre en un centro hermético, autosuficiente, que lleva en si su propia ley (autonomía) y es para sí su propio principio (autarquía). 


\section{Humanismo y principio de inmanencia}

Como aclaración histórica, debo anticipar que el humanismo es un título específico de la modernidad. La cultura antigua no podía ser humanista por estar polarizada, teórica y prácticamente, en la idea ejemplar de "naturaleza" (physis) como orden impersonal y trascendental del ser. Tampoco la cultura medieval alcanzaba a serlo, por su determinación teológica, orientada prevalentemente al reino de Dios. Como asegura Karl Löwith, "la filosofía se torna antropológica en la misma medida en que el hombre se emancipa del cosmos divino de los griegos y del Dios trasmundano de la Biblia y finalmente asume la creación del mundo mismo". Aun cuando hay una inspiración cristiana y cristológica en la filosofía moderna, desde Cusa a Hegel, es preciso señalar, no obstante, como lo hace Maritain para evitar equívocos, su indeclinable tendencia a convertirse en el culto del hombre. "Es, si se quiere, la edad del Hijo del hombre, pero en la que se pasa del culto al Hombre/Dios, del Verbo hecho hombre, al culto de la Humanidad, del puro hombre" (OO. CC. 6, 312-313). Sin duda, la definición que mejor cuadra a esta nueva edad en que emergen los poderes de una nueva civilización del aquende: el mundo científico/técnico, como dominación de la naturaleza, y la constitución del Estado moderno en cuanto forma de dominio de la necesidad social, determinan el reino del hombre, a diferencia del regnum Dei de la tradición medieval:

Es esto lo que se puede llamar el humanismo separado o antropocéntrico, o incluso, el liberalismo (entiendo esta palabra en el sentido que tiene en el vocabulario teológico, en el que designa la doctrina por la cual la libertad del hombre no tiene otra regla de medida que ella misma $(\mathrm{HI}, 114 ; 6,414)$.

Pero, paradójicamente, esta emergencia del orgullo de ser hombre ha estado acompañada, a juicio de Maritain, de una conciencia ambivalente, exasperada a veces como en la Reforma, de su intrínseca menesterosidad:

Con el Renacimiento es el grito de su grandeza y de su bondad el que hace subir hasta el cielo; con la Reforma es el grito de su desamparo y de su miseria. De todas formas, la criatura demanda, ya sea gimiendo, ya sea rebelándose, su propia rehabilitación. ¿¿Qué significa esta reivindicación? La criatura reivindica el derecho a ser amada? (HI,34;6, 324).

Ahora bien, lo sorprendente es que esta rehabilitación de lo humano no se produjo, en su comienzo, al modo de una rebelión prometeica frente a Dios o un olvido de su existencia, sino como una lenta absorción progresiva de los atributos y funciones, que estaban reservados a la Transcendencia en el antiguo orden metafísico/teológico. No hubo un corte traumático. Fue más bien la ingestión y asimilación de lo divino en la forma de un nuevo principio autónomo. Por así decirlo, el nuevo hombre no nació en una matriz naturalista, sino pneumática, y 
de ahí que aparezca con el extraño esplendor de un ídolo. El principio filosófico de esta absorción reductiva se llama 'inmanencia'. Como señala Maritain, "la clave, todavía aquí, es el presupuesto de una metafísica inmanentista absoluta" $(H I, 62 ; 6,356)$. Se entiende por inmanencia la pretensión, a partir de Descartes, de encontrar en la autocerterza del cogito, esto es, en la autoconciencia, el criterio decisivo de toda verdad. Como se ha hecho notar por diversos intérpretes, el principio de la inmanencia es implícitamente cristiano, -al menos en Descartes, a partir de la interioridad agustiniana, in interiore homine habitat veritas-, pero virtualmente ateo, porque la nueva interioridad acaba cerrándose sobre sí misma. No necesita negar o combatir a Dios, porque comienza integrándolo como una dimensión de la propia autoconciencia, la idea de lo infinito y lo perfecto, que marca la envergadura absoluta del nuevo proyecto de ser hombre. Aparece así el sujeto moderno como el nuevo atlante, solitario y soberano en su reino, que soporta el mundo objetivo. De ahí vino la progresiva reducción de la realidad a objetividad, como ha mostrado Heidegger, aquello que puede ser representado por la conciencia en una idea clara y distinta. Puesto que el fundamento es un esse como percipere, lo fundamentado es un esse como perceptum o cogitatum. Se produce así la nueva división de la realidad en subiectum y obiectum, y con ello, la reducción de la verdad del ser a la certeza y la rectitud representativa ${ }^{3}$. He aquí el círculo cerrado de la nueva economía de la inmanencia: el sujeto no puede tenerse a sí mismo sino en la medida en que se proyecta y construye un mundo objetivo, pues sólo en este medio consuma su propio proyecto existencial; pero, a su vez, el objeto solo queda garantizado en virtud de la acción pro-positiva del cogito, que propiamente es voluntas, voluntad de aseguramiento y dominio de la realidad, voluntad de poder.

Todavía en Descartes, la idea de Dios es la más natural e íntima de la criatura, como el sello dejado en ella por su creador De alguna manera sirve para delimitar la propia conciencia de finitud, $y$, asegurase, a la vez, como un reaseguro del propio cogito, de que el mundo objetivo de la representación tiene, además, un alcance real. En Kant, sin embargo, se trata sólo de un mero ideal trascendental de la razón, su arquetipo de lo que es integral y completo, como canon regulativo de su trabajo. Y, por último, en Hegel, al superar definitivamente la conciencia dualística de lo finito e infinito y la vivencia agónica de esta tensión en la autoconciencia desgraciada (la conciencia cristiana), la idea Dios acaba siendo la Idea lógica absoluta, en que se resuelve la unidad del concepto y la realidad, esto es, la revelación del espíritu absoluto en la realidad efectiva del mundo, labrado por

${ }^{3}$ M. HeidegGer (1997) "La época de la imagen del mundo", en Caminos de bosque (Holzwage, 1950), ed. de A. Leyte y H. Cortés, Madrid, Alianza, 87-91. 
la cultura moderna. Hegel consuma así el inmanentismo de la filosofía moderna y le confiere su pleno significado como la integración de lo divino en el curso del mundo. En esto consiste para él la "muerte de Dios", que no tiene que ser aceptada con trenos y lamentaciones, sino en la lucidez de un nuevo tiempo pleno de libertad:

Esta dura expresión es la simple expresión del simple saber de sí mismo más íntimo, el retorno de la conciencia a las profundidades del yo=yo, que no diferencia ni sabe ya nada, fuera de ella. Este sentimiento es, pues, de hecho, la pérdida de la sustancia y de su enfrentamiento a la conciencia; pero es, al mismo tiempo, la pura subjetividad de la sustancia o la pura certeza de sí mismo que a ella le faltaba, como el objeto, o lo inmediato o la pura esencia Este saber es la espiritualización por la cual la sustancia ha devenido sujeto, su abstracción y carencia de vida han muerto, por medio de la cual, por tanto, la sustancia ha devenido realmente autoconciencia simple y universal ${ }^{4}$.

Con razón Maritain atribuye a Hegel la responsabilidad fundamental en la consumación del inmanentismo y en línea con esta interpretación puede declarar Cornelio Fabro que "el método de Hegel es la síntesis de todos los momentos ateizantes de la época y realiza el profanum essentialem al que tendía el principio de la inmanencia"5.

Pero el humanismo entraña, además, una concepción naturalista del hombre. Esto exige, como ha mostrado Maritain, una última reducción materialista de lo humano. Ciertamente, como ya he señalado, el hombre moderno ha nacido en un matriz espiritualista, y no por casualidad, su culminación, según Hegel, se muestra en la eclosión en la historia del espíritu absoluto. Hay, pues, una segunda línea reductiva dentro de la inmanencia, -Maritain la llama "sustitutiva", pues se lleva a cabo en un proceso de sustitución, por la cual el espíritu cede el paso a la materia e invierte su sentido en la dialéctica materialista (Feuerbach y Marx). Se alcanza así "un inmanentismo realista absoluto-dice Maritain- y esta vasta proliferación ideológica de resentimiento y de indignación no hubiera sido posible sin Hegel" $(H I, 52 ; 6,345)$. ¿ Cuál ha sido la lógica de este proceso de sustitución? En primer lugar, la pérdida de la primacía del acto sobre la potencia, tal como había sostenido la filosofía griega, y luego la escolástica tomista. Como se sabe, esta primacía del ser sobre el poder-ser implicaba para Aristóteles la existencia de una inteligencia separada, autárquica, en puro acto de sí, como condición del movimiento ontológico en el mundo. En Hegel se invierte la situación. La primacía de la potencia o del ser-en-potencia, dicho en términos dialécticos, la identidad ser-nada en

${ }^{4}$ G. W. F. HeGel (1966) Fenomenología del espíritu (1807), traducción al castellano de W. Roces, Madrid, FCE, 455.

${ }^{5}$ C. FABRO (1969) Introduzione all'ateismo moderno, Roma, Studium, 535 y 537. 
el comienzo y como condición de comienzo, y la primacía del proceso sobre el acto, que no es más que resultado del mismo, preparan la posterior reducción materialista, que consuma Marx. Consecuentemente con la nueva primacía de la potencia, se produce la inversión de la causalidad formal por la material, esto es, de lo que es principio de posibilitación ontológica a lo que sólo es principio de originación empírica. Bien es cierto que en esta tarea de invertir el espíritu absoluto hegeliano hay que contar la crítica de Feverbach a la criptoteología hegeliana, y muy específicamente al concepto de religión, que era una instancia clave en el pensamiento de Hegel; y con ello la emergencia de una posición sensualista y naturalista. Pero los presupuestos ontológicos del materialismo radical ya estaban en Hegel. Se comprende, por tanto, que Marx, aun separándose del naturalismo mecanicista y objetivista de Feverbach, haya culminado el materialismo, mediante la inversión de la dialéctica hegeliana, y en virtud del mismo principio que inspira a ésta: la primacía del poder-ser y el papel creador del trabajo o de la actividad humana como el medio de autoconstitución del hombre.

La síntesis histórica de trascendentalismo inmanentista y de naturalismo o materialismo, ya sea mecanicista o dialéctico, que constituyen los dos grandes nódulos críticos de la modernidad, es decir, la aparición de la tesis del homo-mensura, de un lado, y del otro, del homo faber o constructor de sí mismo, posibilitan que el humanismo moderno se cierre sobre sí como una filosofía del aquende, absolutamente ciega a la Transcendencia. Decía antes que en el humanismo antropocéntrico el hombre aparece como un ídolo. Espero que aquella extraña afirmación resulte ahora comprensible. La consumación del proceso reduccionista hace que a su término el hombre aparezca dotado de aquellos atributos que la metafísica ontoteológica reservaba para Dios, la aseitas, el tener el ser en virtud de sí mismo, y la autarquía y soberanía de lo absoluto, que se desplazan al reino del hombre, y en especial, al Estado moderno, como el Dios efectivo. Obviamente este ídolo humanista no es el hombre concreto y singular, en su contingencia y menesterosidad constitutivas, sino el hombre total o el todo de los hombres, el género (Gattung) como compendio (Inbegriff) del valor total de lo humano. Este desplazamiento del humanismo del mero hombre al humanismo del género va a tener extraordinarias consecuencias en el orden político. Ya se elija la línea del humanismo liberal burgués o la del humanismo comunitario/socialista, la consecuencia inevitable de la tesis del homo-mensura, es la entronización del Estado, como el último sujeto de una cultura de la autarquía y la soberanía. Creo que el mérito fundamental de Maritain ha consistido en mostrar la lógica inevitable de esta transferencia del discurso humanista a la esfera pública o estatal. Tan pronto como se deja el hombre abandonado a sus solas fuerzas y en la medida en que se quiere superar su condición de criatura hay que transferirlo e integrarlo en un 
nuevo orden artificial, absolutamente autárquico y soberano, que es el Estado. La antropocracia, en cuanto voluntad de poder, termina siendo, en verdad, estatocracia, que consiste en "la reivindicación del hombre entero para el todo, sea colectividad o Estado $(H I, 142$, nota 5; 6, 445). Este intento de superación de la criatura es especialmente visible en Hegel para quien lo finito es algo que, por insuficiencia, tiene que desaparecer:

En la perspectiva hegeliana -escribe Maritain- finitud y contingencia sólo pueden tener lugar como datos de lo inmediato (irracionales), que, de fase en fase, están sometidos a los procesos y conflictos del desarrollo, cuyo objeto es negarlos y superarlos o sublimizarlos $(\mathrm{FM}, 206 ; 11,446 \ldots)^{6}$.

Si se adopta la línea específica del humanismo liberal, con su concepto del individuo abstracto como fuente última de valor, puesto que su libertad es entendida como espontaneidad de acción o conatus exento de impedimento, hay que concluir, como coherentemente hace Hobbes, que el estado natural no puede ser otro que guerra o confrontación, de la que sólo se puede salir mediante la limitación de su poder y la transferencia de la potencia cedida al Estado, cuyo poder soberano surge de esta reapropiación. Maritain reconoce de buen grado al liberalismo su capacidad crítica para debelar instituciones arbitraras y sistemas dogmáticos de pensamiento en nombre de la nueva libertad, pero su fuerza es puramente negativa $(H I, 164 ; 6,470)$, ya que no puede establecer un régimen jurídico válido sin la limitación del mismo presupuesto en que se funda. Pero si, por el contrario, se adopta la otra línea, la que va de Rousseau a Hegel, a partir del individuo como singular inmediato, parte de un todo, resulta evidente que su libertad, en cuanto auto-determinación racional, tiene que orientarse necesariamente a un bien público, que surge de la renuncia o sacrificio del individuo a su propio interés en aras de lo universal. Como denuncia Maritain, dentro del espíritu subjetivo el libre arbitrio es un "momento ilusorio", pues esta ligado a la presión de fuerzas naturales de atracción; la auténtica libertad es sólo la de autonomía o determinación racional, pero esta es puro formalismo, y su determinación concreta sólo se alcanza en el espíritu objetivo, cuando el espíritu subjetivo se comporta en su pura necesidad racional (FM,211 y 215). Ahora bien, este orden ético pertenece al Estado. Tanto en la fórmula rousseauniana como en la hegeliana, la voluntad general o universal acontece en el Estado. En cualquiera de estas dos concepciones del Estado moderno, se trata de un Estado cuerpo artificial, dotado de una razón absoluta y un poder soberano. Como escribe Maritain, a propósito de Rousseau:

6 J. MARITAIN (1966) Filosofía moral (Princeton 1959), Madrid, Morata, 206. En lo sucesivo será citado por la sigla FM y la referencia a OO. CC. 11 (1991). 
El mito de la voluntad general, que no es una simple voluntad mayoritaria, sino una voluntad monádica superior e indivisible, que emana del pueblo como voluntad y que es siempre recta, no era más que un medio de transferir al pueblo el poder soberano y trascendente del rey absoluto $(\mathrm{HE}, 58 ; 9,530-531)^{7}$.

La voluntad general acaba siendo la culminación de la autoconciencia moderna, pensada en cuanto voluntad de poder. En Hegel esta voluntad es calificada expresamente como divina, y de ahí su dignidad. "Si todo el Estado es espíritu objetivado, sólo en calidad de uno de sus miembros es como el individuo mismo posee objetividad, verdad y vida ética" (FM,217). He aquí -concluye Maritain- "la fórmula misma, la fórmula original del totalitarismo político" (lbíd.). No es extraño, pues que el Estado moderno se beneficie, en cuanto órgano de la colectividad, de los caracteres específicos de lo absoluto, y aparezca así como el depositario de la soberanía (poder irrestricto) y de la autarquía (poder que se basta a sí mismo en su incondicionalidad), con un derecho inalienable sobre los ciudadanos, que acaban siendo sus súbditos e inmolándose a este nuevo ídolo, al que han transferido su propio poder (HE, 48-52; 9, 521-525). Como ha visto certeramente Maritain, en El hombre y el Estado, la concepción jurídica de la soberanía como poder separado del pueblo y trascendente a él (por encima del pueblo) producto de una cesión o y transferencia irreversible (Hobbes) es el rostro definido de lo divino en la edad moderna. No en vano Bodin toma al soberano como imago Dei y Hegel lo convierte en la presencia de Dios en la tierra. La misma metáfora de la personificación del Estado $(\mathrm{HE}, 224 ; 9,707)$ traduce inequívocamente la des-animación de la vida personal ante el Estado y su traslado a esta nueva persona jurídica, cuya "razón de ser", la llamada razón de Estado, está por encima de la vida y la propia conciencia individual. Hay, pues a juicio de Maritain, una secreta alianza, pese a su divergencia primera, entre el individualismo y el totalitarismo, porque sólo el individuo, en razón de su particularidad, tiene que ser inmolado al todo, y recíprocamente, sólo se puede implantar un régimen totalitario, homogeneizador y arrasador de toda diferencia, sobre la unidad discreta de los individuos, cuya suma arrojaría una fuerza de entidad superior.

7 J. MARITAIN (1983) El hombre y el Estado (París 1953, PUF), Madrid, Encuentro, 58. En lo sucesivo será citado por la sigla HE y la referencia a OO. CC. 9 (1990) 530-531. 


\section{La rectificación del humanismo}

Desde la madurez de la edad moderna, en un célebre pasaje de la Fenomenología del espíritu, veía Hegel el alma cristiana como una autoconciencia desgraciada, escindida interiormente entre dos polos de sí misma, el allende y el aquende, lo infinito/inmutable y lo finito/pasajero, a los que no podía renunciar ni conciliar. Sólo a lo largo de la experiencia de este martirio, de este conflicto interior, podía aprender a cancelar, a través de su propia acción, ese doble mundo, reconciliándose consigo misma e ingresando así en la esfera de la razón. Maritain conoce la trascendencia de este pasaje dialéctico, y por eso, devolviéndole a Hegel la moneda, le reprocha a la razón moderna ese mismo estilo trágico que ella creía tener superado definitivamente. El desgarramiento reside ahora en el desajuste entre las creencias, en las que se presume estar y las consecuencias que se siguen de facto de la mismas. Se cree en la libertad incondicional pero se acaba transfiriéndola a otras instancias foráneas de decisión; se afirma la primacía de la conciencia, pero se rinde culto a la opinión institucionalmente establecida; se rechaza toda religión, pero se levantan altares a nuevos ídolos como la clase social, el partido, la nación o el Estado moderno. Y su causa está, según Maritain, precisamente en el principio inmanencia que determina en su raíz toda la cultura moderna, echando a perder sus mismos esfuerzos y conquistas, pues "las verdades y valores que la historia engendraba están congénitamente viciados por una falsa metafísica" $(\mathrm{HI}, 148 ; 6,452)$. Al cerrarse a la trascendencia, los condena a la esterilidad del más extremo relativismo, del que sólo caben dos salidas: o la alienación de la propia conciencia en una esfera impersonal y anónima o bien la consumación del nihilismo. Se comprende así todo el alcance de la rotunda conclusión de Maritain:

Si el ateísmo pudiera ser vivido en la raíz del querer, desorganizaría, mataría metafísicamente la voluntad, y no es por accidente sino por un efecto estrictamente necesario, inscrito en la naturaleza de las cosas, que toda experiencia absoluta del ateísmo, sin es conducida científica y rigurosamente, provoca al fin la disolución psíquica $(\mathrm{HI}, 68 ; 6$, 362-363).

La aseitas o autosuficiencia ontológica, pretendida en la modernidad por la criatura - la acaba a ésta destruyendo al disolverla en instancias supraindividuales, en las que no puede reconocerse en cuanto tal, o la acaba precipitando en un culto desenfrenado de sí en su escueta singularidad, en la voluntad del Único (Max Stirner, 1806-1856) que no deja subsistir nada fuera de sí mismo, de su infinita voluntad de poder. En el momento de máximo paroxismo de la cultura moderna, en el espacio histórico de entreguerras en una Europa desangrada en guerras civiles entre sus hijos, la autoconciencia moderna alcanza a ver la contradicción interna de su humanismo. Sus dos formas denuncian la extrema indigencia a que 
se ha llegado. De un lado, el humanismo liberal deja traslucir "la falsa conciencia" del alma burguesa, que pese a s u culto retórico a los grandes ideales, acaba entronizando una sórdida cultura materialista. El hombre burgués "aparece como la producción farisaica, decadente, nacida del espíritu puritano o jansenista y del espíritu racionalista" $(H I, 86 ; 6,382)$. Este hombre ha creado tan sólo una cultura nominalista del 'signo' -la opinión en la vida política y el dinero en la vida económica" (Ídem)-, que corrompe nuestro saludable sentido de lo real. Del otro lado, el humanismo socialista ha mostrado, según Maritain, un sentido más vivo de la realidad inmediata y la suerte concreta del hombre, una conciencia más aguda de los grandes valores humanistas, como la dignidad del hombre o el ideal de una justicia integral, e incluso del sentido religioso de la vida como realización de un ideal absoluto, pero el despotismo burocrático y el totalitarismo político con su desprecio a la persona humana, amenazan con una total "socialización del espíritu" o "administración del yo" (HI,92).

No es de sorprender si en este clima extremo de decadencia espiritual se impone un punto de inflexión. Ahora bien, toda esta empresa de salvación supone que hay algo que merece ser salvado y que se cuenta, además, con un principio salvador 0 renovador, capaz de infundir nueva vida o reanimar viejas creencias y valores que se han echado a perder. ¿Qué merece ser salvado del humanismo antropocéntrico? Sin ser hegeliano en la interpretación de la historia, Maritain reconoce que una época, por haber sido vivida, ha quedado ya sobrepasada; sería vano empeño pretender hacerla volver en su forma inmediata, en el tipo que encarnó, porque en su acontecer ha agotado ya su virtualidad. Se diría que se pueden conservar los espíritus de cada época, transmutados o sublimados, pero en modo alguno su cuerpo o estructura cultural e institucional. Una vuelta a la cristiandad medieval es tan impracticable e insensata como la inercia de mantenerse en una modernidad, cuya grave deficiencia se ha experimentado ya larga y catastróficamente. Pero hay valores liberados por cada época histórica, que deben ser guardados para una nueva reacuñación. Tal es el caso en la modernidad de aquellos valores, a los que no se puede renunciar sin mutilar la herencia histórica de la humanidad. Entre ellos hay que contar la autonomía del sujeto individual frente a toda instancia heterónoma; el sentimiento de dignidad de la persona, que aun cuando siendo de filiación cristiana, ha asido desarrollado y cultivado en buena parte del pensamiento moral moderno (Rousseau, Kant, Fichte); la primacía de la conciencia moral, como instancia de juicio y discernimiento; la construcción de la ciudad terrestre sobre el ideal de la "conquista y realización de la libertad".

Maritain subraya repetidas veces que tales valores son de procedencia cristiana, y por éso sólo el cristianismo podrá salvarlos de su corrupción por obra del sub- 
jetivismo y el totalitarismo. Son, pues, valores desafectos de su origen y a los que es preciso devolver a "la plenitud de su fuente originaria" $(\mathrm{HI}, 14)$. Como escribe en otro momento, la civilización moderna es un vestido muy usado, al que no se le pueden coser piezas nuevas:

Se trata, pues, de una refundición (refonte) total y como sustancial, de una inversión (renversement) de los principios de la cultura, puesto que se trata de llegar a una primacía vital de la calidad sobre la cantidad, del trabajo sobre el dinero, de lo humano sobre lo técnico, de la sabiduría sobre la ciencia, del servicio común de las personas humanas sobre la codicia individual de enriquecimiento indefinido o la codicia estatal de poder ilimitado $(\mathrm{HI}, 212)$.

Ahora se percibe el alcance de la expresión "humanismo integral", no en sentido cuantitativo (el todo de la tradición humanista) sino cualitativo, recriado en una nueva forma o actitud metafísica y ética, en que queda salvado y trascendido. En algún momento llama a este humanismo "teocéntrico, por oposición al antropocéntrico: pero de inmediato corrige su expresión en un sentido preciso, cristocéntrico," enraizado -dice- alli donde el hombre tiene sus raíces: humanismo integral, humanismo de la encarnación" (HI,80; 6, 376).

¿Cómo salvarlos? Sacándolos de su matriz inmanentista en el cogito moderno y situándolos en una perspectiva de Transcendencia. Maritain cree que el cristianismo se haya en condiciones, en virtud de su fe en la persona humana, de emprender esta empresa de salvación, a la que llama rectificación del humanismo, no entendido como una simple corrección de rumbo, sino como una reacuñación sobre un principio recto o adecuado de viejas categorías que necesitan de un nuevo troquel. Dos son los principios que operan en esta transformación. El primero el pneumático/religioso de la encarnación, que permite comprender la primacía de lo espiritual, no como una fórmula de la dominación, en sentido medieval, sino de inspiración y asunción encarnatoria. Ya en Science et sagesse, de esta misma época, apunta la idea de "una civilización humanista integral que descendiendo de las culturas sagradas de la fe hasta el borde extremo de lo profano y de lo humano, libertaría toda la verdad de lo profano y de lo humano"8. Como precisa luego en Humanismo integral, la estrella de orientación de esta empresa no será ya "el imperio sagrado de Dios, sino la santa libertad de los hijos de Dios" (HI, 169; 6, 476: "... ce ne serait plus l'idée de l'empire sacré que Dieu possède sur toutes choses, ce serait plutôt l'idée de la sainte liberté de la créature que la grâce unit à Dieu"). Es todo un giro radical a la política teocrática fundada en una comprensión dominadora de la fe. Para Maritain, la primacía de lo espiritual no es despótica

${ }^{8}$ Cfr. H. BARS (1962) Maritain en nuestros días, Barcelona, Estela, 258. 
sino emancipadora, en un sentido inspirativo. Cuando establece las relaciones entre lo espiritual y lo temporal se cuida siempre de subrayar que lo temporal no juega un papel instrumental y subsidiario de lo espiritual, y que éste, a su vez, tiene la primacía, no por subordinación o mando, sino por presencia inmanente y transfiguración. Y cuando se refiere a la nueva conciencia evangélica la caracteriza por "un respeto evangélico de la naturaleza y de la razón, y de aquellas estructuras naturales que el humanismo moderno ha servido para descubrir, pero que no ha sabido preservar" $(\mathrm{HI}, 85 ; 6,381)$.

Contrasta así la actitud de Maritain con la que unos años más tarde, al término de la segunda guerra mundial, en coyuntura semejante, fue adoptada por Martin Heidegger en su célebre Carta sobre el Humanismo. Decía allí el pensador de la Selva Negra

La grandeza del hombre no descansa con seguridad en que sea la sustancia (Substanz) del ente en como sujeto (Subjekt) del mismo, para que en cuanto poseedor de la esencia del ser (Machthaber des Seins) dejar disolver el ser del ente en la célebre objetividad. El hombre es más bien el arrojado por el ser mismo en la verdad del ser, de tal modo que ec-sistiendo, cuida de la verdad del ser, para que a su luz pueda aparecer el ente en cuanto tal'.

Y frente a la orgullosa y arrogante subjetividad moderna, que cree poder disponer del ser de lo ente, proponía Heidegger la nueva idea del ec-sistente (Da-sein) como su guardián. "No el señor (Herr) del ser, sino su pastor (Hirt des Seins) ${ }^{10}$. Sin negar profundas afinidades entre ambos proyectos, los diferencia fundamentalmente la línea que va desde la religión revelada al pensar esencial postmetafísico. Sus afinidades son, fundamentalmente de carácter negativo, erradicar el concepto de subjetividad moderna y en su lugar entender al hombre como éxtasis del ser, abierto a su verdad. Los dos, Maritain y Heidegger, coinciden en su lucha contra el antropologismo de la cultura moderna de interpretar y evaluar toda cosa en función exclusiva del hombre, $y$, por tanto, los dos denuncian el antropocentrismo como reducción del ser a la medida del interés humano. Los dos encaran el principio de la inmanencia, al que hacen responsable de la penuria de la cultura moderna de meros signos sin sustantividad ontológica y los dos se proponen superar esta clausura de la autoconciencia mediante el ámbito de la apertura (Offenheit), en que se haga patente la pertenencia del hombre a la verdad del ser. En este sentido

\footnotetext{
${ }^{9}$ M. HeIDEGGER (1957) Lettre sur l'Humanisme, ed. bilingüe germano-francesa de Roger MuNIER, París, Aubier, 70-72; Madrid 1966, Taurus (reeditada en Madrid 2004, Alianza).

10 Ibíd., 104.
} 
escribe Maritain, "los principios específicos de la filosofía, llamada moderna (...) al comportar indocilidad respecto del ser (...) son falsos desde su raíz" ${ }^{\prime 1}$.

Pero ambos proyectos difieren radicalmente en sus presupuestos respectivos: encarnatorio en Maritain y gnóstico en Martin Heidegger. Dicho en otros términos, el primero libera el humanismo integrándolo en una nueva clave; el segundo se libera del humanismo como de un campo de extravío metafísico, abandonando lo ente para fugarse hacia la verdad de un ser, que siempre se escapa. En Maritain, el presupuesto de la encarnación lo va a llevar a una metafísica del ser, toto coelo distinta de la heideggeriana. Para Heidegger, "no sólo el humanismo, en su determinación de la humanidad del hombre, no plantea la cuestión de la relación del ser a la esencia del hombre, sino que impide plantearla, no conociéndola ni comprendiéndola por la razón de que tiene su origen en la metafísica"12. Heidegger rompe con el humanismo porque entiende que en él toda teoría del hombre se apoya o bien en una esencia metafísica y prototípica de lo humano o bien en un acto metafísico de la existencia humana en cuanto subjetividad fundante; es decir, todo humanismo o presupone una esencia del hombre, a la que ajustarse, o pone la existencia del hombre como nuevo fundamento. En ambos casos, deja de pensar la relación del ser a la esencia del hombre, o a la inversa, de la ecsistencia con la verdad del ser. Pero esta verdad, que ya no puede ser metafísica ni teológica, se reserva en el misterio (Geheimniss) de un fondo insondable que escapa a toda penetración y apropiación intelectual, que sería, según Heidegger, objetivadora y cosificadora. De ahí que se trate de un integral no-humanismo desde una instancia anti-metafísica. En cambio, en Maritain, lo específico del humanismo no es su carga metafísica, sino la desgravación ontológica que hace del hombre al constituirlo como fuente de toda medida. Y para esta reintegración del humanismo en una metafísica omnicomprensiva, que no sea ni esencialista ni existencialista, retoma la metafísica clásica tomista del ser como acto de perfección, que sobrepasa la esencia y la existencia, al fundar a ambas en su intrínseca copertenencia. Como ha escrito Henry Bars, "el humanismo integral tiene como su fuente más profunda y más culta la metafísica del esse, que es la de santo Tomás de Aquino y cuyo origen es cristiano"13. En otros términos, la trascendencia de que habla Heidegger, es la de una reserva de significación insondable, o de una pura potencia, mientras que para Maritain es la Transcendencia real de la plenitud de

${ }^{11}$ Cfr. H. Bars, Maritain en nuestros días, op. cit., 202.

${ }^{12}$ M. Heidegger, Lettre sur l'Humanisme, op. cit., 46. El subrayado no pertenece al texto.

${ }^{13} \mathrm{H}$. BARS, Maritain en nuestros días, op, cit., 269. 
un acto de ser, como perfección intensiva, que sólo se da por participación en la criatura. Una prueba de esta diferencia radical entre ambos pensadores es que, mientras Heidegger incluye el concepto de persona dentro de las categorizaciones metafísicas del hombre (cuerpo, alma, conciencia, espíritu) de las que hay que prescindir, Maritain encuentra precisamente en el concepto metafísico de persona, la clave de rectificación del humanismo.

Según Maritain, al igual que la metafísica del esse como acto absoluto, intensivamente infinito, encierra un concepto analógico del ser, que no se deja reducir a ningún univocismo esencialista (el ser como género ) ni disolver en ningún historicismo existencialista (el ser como facies de manifestación histórica), el concepto de persona tampoco puede identificarse con ningún objetivismo esencialista de lo humano ni con ningún subjetivismo. Ser-persona no se funda en ninguna determinación de un ser natural, psicofísico, pero tampoco en ninguna determinación abstracta espiritualista. Ciertamente la persona es espíritu, potencia de libertad, pero espíritu encarnado, $y$, por tanto, adscrito esencialmente a un aquí y ahora, coordenadas estructurales de carácter carnal e histórico, que sobreeleva a una vida humana individual, pero trascendida o abierta al orden de la universalidad (en la verdad y el valor) y de la viviente intersubjetividad. Ser-persona es una condición ontológica, a la que podemos caracterizar por tres momentos decisivos:

1. el excessus, en cuanto referida constitutivamente al Esse absoluto, (capax Dei),al que se trasciende, $y$, por lo tanto, abierta dinámica y trascendentalmente a un término absoluto de su dinamismo de conocimiento y amor.

2. la capacidad de estar presente a sí misma y volver sobre sí misma desde su operación (redire in essentiam suam nihil aliud est quam rem subsiste in se ipsa), en cuanto permanece cabe sí, en la raíz de su acto de ser.

3. la apertura al otro, pues la vocación personal, con sus objetivos y tareas universales, sólo se descubre y realiza en el seno de una comunidad racional, y a lo largo de un incesante ejercicio de comunicación.

Como advierte finamente Maritain, con el concepto de persona se cuenta con una clave decisiva para superar, en el orden práctico/moral, la antinomia de subjetivismo y colectivismo. En numerosas obras, sostiene Maritain, siguiendo estrictamente la doctrina de Tomás de Aquino, que el hombre, en cuanto individuo natural está ordenado teleológicamente al todo, pero en cuanto persona, es decir, en cuanto autor del sentido de su propia vida en el orden del valor, está por encima del todo social, que debe estar supeditado al interés trascendental de la realización del yo 
en su destino y vocación (Cfr HI, 140-142 y 209; 6, 443-446, 492-494). Dicho de modo sumario,

La persona humana en cuanto individuo es para el cuerpo político y el cuerpo político es para la persona humana en cuanto persona. Pero el hombre no es en modo alguno para el Estado. El Estado es para el hombre $(\mathrm{HE}, 27 ; 9,495)$.

\section{Cristianismo y democracia}

Una comprensión integral de lo humano permite situar en un nuevo nivel y reordenar las relaciones viciosas entre lo temporal y lo eterno. Aquí, como en otras cuestiones, la regla de otro de Maritain será distinguir para unir, en lugar de separar para confundir. Tanto la Cristiandad medieval como la Edad Moderna han sido excluyentes y exclusivas. La distinción entre lo sagrado y lo profano era tan tajante y simplista que de hecho no permitía su comunicación, sino la prevalencia abusiva de una sobre otra esfera. Se suponía que son dos órdenes de realidad diferentes e impermeables entre sí. En este sentido, Maritain reprocha a la Cristiandad medieval haber sido víctima de una comprensión "pagana" de lo sagrado $(\mathrm{HI}, 130 ; 6$, 432), al considerarlo como algo separado y dominador. En sentido inverso, podría decirse que la modernidad ha caído en una comprensión demasiado sagrada de lo profano, al erigirlo como un orden absoluto, que reivindica la totalidad de la vida. En definitiva, la falsa distinción conduce de hecho a la confusión de ambas dimensiones, en la forma de la dominación de un orden sobre otro, a costa del otro, contagiándose con algunos de sus elementos: así la Cristiandad se define como régimen político absoluto al igual que la modernidad cree haber realizado en el Estado moderno el sacrum integrale de la existencia.

Al deshacer tan grave confusión, se libera conjuntamente, la autonomía de lo temporal y el trascendentalismo de la fe religiosa, esto es, su heterogeneidad y trascendencia sobre cualquier cultura o régimen político. Como escribe Maritain,

En lo sucesivo lo profano no se opone a lo sagrado como lo impuro a lo puro, sino como un cierto orden de actividad humana cuyo fin es temporal se opone a otro orden de actividades humanas socialmente constituidas en vistas de un fin específicamente espiritual $(\mathrm{HI}, 130 ; 6,432)$.

Para Maritain es obvio que el carácter transcendente de la persona en su destino exige la primacía de la dimensión espiritual, en cuanto concierne a un interés trascendental del sentido y finalidad última de su propia vida, lo que escapa a la competencia de la acción temporal, pero tal primacía no comporta una subordina- 
ción instrumental de parte de lo temporal, sino la apertura del bien común social a los bienes espirituales de la persona:

El cristianismo debe informar o mejor transpenetrar el mundo, no porque éste sea su fin principal (es tan sólo un fin secundario indispensable) ni para que el mundo devenga desde ahora ya el reino de Dios, sino para que la refracción del mundo de la gracia llegue a ser en él cada vez más efectiva y para que el hombre pueda vivir mejor su vida temporal (HI, 119; 6, 420).

La ganancia es, pues, doble. El cristianismo se reconoce en su tarea propia de encarnar su fe religiosa, sin privilegio social alguno, en una cultura secular, inspirando así la idea de una nueva cristiandad, que ni subsista como gheto ni se alce con pretensiones hegemónicas algunas. Y la democracia, a la par que recibe una reanimación moral, al menos motivacional, de parte de una religión cristiana con vocación civil, gana en su interno pluralismo de opciones de vida, al perder lo profano la función directiva y absorbente del todo de la existencia. Así nació en Maritain la idea, a primera vista sorprendente y provocativa de "un Estado laico vitalmente cristiano" (HI, 182; 6, 491), esto es, del pleno reconocimiento de la autonomía del orden temporal, pero con una idea del bien común abierto a los intereses trascendentes de la persona. Conviene ponderar bien esta propuesta: Un Estado laico, esto es, autónomo y democrático, ha de ser intrínsecamente pluralista en las diversas orientaciones ideológicas y formas de vida que acoge en su seno, $y$, por tanto, tiene que haber renunciado a cualquier forma de absolutismo ideológico, que reclame para sí la totalidad de la conciencia. Pero, a la vez, el cristianismo en la ciudad laica tiene también que renunciar a cualquier pretensión hegemónica y mantenerse en pie de igualdad con otras concepciones religiosas o ideológicas de la vida:

Esto significa para nosotros que para evitar males mayores (que serían la ruina de la paz de la comunidad y el endurecimiento -o doblegamiento de las conciencias), la ciudad puede y debe tolerar en ella (tolerar no es aprobar) maneras de adorar que se apartan más o menos gravemente de la verdadera (ritus infidelium sunt tolerandi, enseña santo Tomás), maneras de adorar, y,por consiguiente, maneras de concebir el sentido de la vida y de comportarse; y que la ciudad se decida a acordar a las diversas familias espirituales que viven en su seno las estructuras jurídicas que ella misma en su sabiduría política apropia de una parte a su Estado, y de otra parte, a la orientación general de la legislación hacia la vida virtuosa $(\mathrm{HI}, 173 ; 6,480)$.

No se trata de la tolerancia por indiferencia, tan frecuente en las sociedades avanzadas, sino de una tolerancia por respeto a la autonomía de la persona. Y ha de ser doble, tanto "tolerancia dogmática" de parte de la lglesia, "que tiene la libertad del error como un bien sí", como la "tolerancia civil, que reclama del Estado el respeto de las conciencias" (HI,178; 6, 486). Hoy esta distinción nos 
parece plausible, cuando la fe cristiana, en el concilio Vaticano II, ha reconocido la libertad de conciencia, al igual que lo hace la Constitución española de 1978 (a. 16), incluyéndola entre los derechos fundamentales del hombre. Pero a la altura de 1934, en la pleamar de los totalitarismos de uno u otro signo, y con una Iglesia enrocada en su ciudadela espiritual, constituía una santa osadía formular en estos términos la cuestión.

Desde el punto de vista de una filosofía de la cultura y de la historia, la nueva cristiandad pretendía ser una nueva figura de existencia histórica del cristianismo, tras el ciclo medieval y el moderno, en la que pudieran convivir ambas dimensiones de lo temporal y lo espiritual sin destruirse ni ignorarse. No obstante, el concepto de nueva "cristiandad" puede suscitar el equívoco de una vuelta nostálgica al régimen de la cristiandad medieval. Maritain se apresura a aclarar que lo utiliza analógicamente $(\mathrm{HI}, 144$ y $146 ; 6,448-451)$ en la medida en que el cristianismo se puede acomodar a distintas condiciones históricas y estructuras socio-culturales. Se trata, pues, de evitar tanto una versión unívoca del concepto en un sentido absolutista, como una interpretación historicista y nominalista del mismo. A tenor de lo dicho, la nueva cristiandad, que piensa Maritain, no hay que entenderla de ningún modo como una civitas cristiana, sino como un "ideal histórico concreto" $(\mathrm{HI}, 135$ y $139 ; 6,437$ y 442), realizable en mayor o menor grado, y consistente "en un cierto régimen común temporal, cuyas estructuras llevan, según grados y modos muy variables, el sello de la concepción cristiana de la vida" $(H I, 139 ; 6$, 442). Pese a todo, el término "cristiandad" arrastra, a mi entender, connotaciones muy fuertes y precisas de su pasado medieval, que lo hace sospechoso a la sensibilidad moderna, aparte de que la tendencia irreversible del mundo moderno a una plena secularización así como el pluralismo cultural hacían en gran parte utópica esta ciudad laica, virtualmente cristiana. Todavía, tras la segunda guerra mundial se abrió en Europa la posibilidad de una presencia social pública del cristianismo en la forma de un partido confesional como la "democracia cristiana". En lo sustancial lo que Maritain pretende es un nuevo modo de vivir el cristianismo en la ciudad secular para que éste logre ser social y políticamente relevante y fecundo. Es también el intento de dotar al cristianismo de vigencia, no institucional, sino vital y cultural en la época secular. Naturalmente esta vigencia pasa por el compromiso temporal del cristiano, tratando de aportar a las tareas de la democracia el impulso renovador de su fe. Sin embargo, esta presencia no supone una fuerza política confesionalmente cristiana. En alguna ocasión se refiere a un "tercer partido", entre el liberalismo y comunismo, pero no reducido exclusivamente a los cristianos, sino como un conjunto de hombres de buena voluntad que defienda una concepción personalista de la vida, aun cuando duda si no es ya demasiado tarde para ello $(\mathrm{HI}, 270$, nota). Pero, en general, Maritain se opone a la presencia confesional de 
lo cristiano en política, y mucho más aún, a una "presencia larvada" o secreta con la única intención de la conquista del poder. En definitiva, en la nueva cristiandad lo dominante no habría de ser el cristianismo político ni la política cristiana, en el sentido formal y confesional del término, sino una nueva conciencia evangélica "respetuosa con la naturaleza y la sociedad" y dispuesta a asumirlas e inspirarlas desde la fe, pero sin reclamar para sí privilegio ni derecho institucional específico.

Obviamente una ciudad laica ha de tener algún sistema de creencias y valores, pero su unidad no ha de ser máxima, -ni un absolutismo de la fe ni de la razón, lo que iría en contra del pluralismo- sino "minimal, aunque orgánica, estando situado su centro de formación y de organización en la vida de la persona" $(\mathrm{HI}, 177 ; 6$, 485). Por consiguiente, no se trata de una unidad ideológica en alguna filosofía común, con la que la modernidad ha intentado inútilmente, a su juicio, paliar la perdida unidad en la fe; tampoco de una religión civil al modo de Rousseau $(H I, 179)$. "Es preciso renunciar a buscar -escribe- en una común profesión de fe la fuente y el principio del cuerpo social" $(H I, 179 ; 6,488)$. ¿Qué resta, pues? Una "unidad de amistad fraterna" o de amistad civil, aun cuando en Humanismo integral no se especifica el contenido sustantivo de la misma. "Buscar establecer un minimum doctrinal común (...)-dice- es pura ficción. Cada uno se compromete y debe comprometerse todo entero a dar su máximo" $(H \mathrm{H}, 210 ; 6,522)$. En cambio, en El hombre y el Estado, se refiere a una común fe democrática,

fe secular en lo que atañe a las convicciones prácticas, que la razón puede intentar justificar (con mayor o menor éxito, eso es asunto distinto) desde perspectivas filosóficas completamente diferentes (...), de las que el corazón humano llega a ser capaz con el progreso de la conciencia moral y que, de hecho, han sido despertadas por la levadura evangélica que fermente en las oscuras profundidades de la historia (HE, 130; 9, 611).

Su contenido son los derechos humanos, frontera de la conciencia ética de nuestro tiempo. Sin duda es posible y hasta necesaria una interpretación de tales derechos en clave personalista. De ahí que "esta obra común, no sea sacral cristiana, sino profano cristiana" $(\mathrm{HI}, 211 ; 6,522)$. No hay, pues, ni debe darse una predominancia del momento religioso sobre el ético, salvo en la inspiración última, pues Maritain comparte la opinión de Bergson de que "el sentimiento y la filosofía democrática tienen sus más profundas raíces en el Evangelio ( $\mathrm{HE}, 76 ; 9,550)$ y, en consecuencia, "la democracia sólo puede vivir de su inspiración evangélica" (HE,77; 9, 550). Oír esta abierta confesión de un pensador creyente, cuando tantas sospechas se han levantado por parte del catolicismo contra la democracia, reconforta el ánimo. Es cierto que en su lenguaje, excesivamente calcado sobre planteamientos tomistas, Maritain sigue hablando de que el fin del Estado, aun siendo autónomo y pleno en su línea de procurar el bien común, es "infravalente" con respecto al fin espiritual 
y debe orientarse a él, pero más allá de esta refícula escolástica, que en ocasiones tanto le estorba, de lo que se trata sustancialmente es de edificar entre todos una ciudad de personas o un bien común integral, de tal modo que "subordinándose a esta obra común, cada uno se subordina al cumplimiento de la vida personal de los otros, de las otras personas" $(\mathrm{HI}, 210 ; 6,521)$.

Una concepción así modifica radicalmente los términos en que se suele plantear la relación del Estado con la Iglesia. La laicidad del Estado, como corresponde a su autonomía e independencia, no puede significar, sin embargo, una actitud beligerante ni siquiera indiferente con respecto a la religión, sino abierta y cooperadora con la Iglesia; pero a la que ha de corresponder de parte de ésta una actitud de lealtad a los contenidos y valores de la fe democrática. La cooperación puede variar según las condiciones históricas:

Hasta aquí era sobre todo el modo de la potencia temporal misma y de los constreñimientos legales; en el porvenir puede ser, sobre todo, el modo de la influencia moral en las mismas conexiones político-religiosas" (HI, 184; 6, 493).

En Humanismo integral se contempla entre el Estado y la Iglesia o bien un régimen de cooperación estatutaria privilegiado en virtud de la relevancia social e histórica de una determinada confesión religiosa, o bien, un régimen de integración de las actividades cristianas, (educativas y asistenciales) de la lglesia en la "misma obra temporal, en el modo pluralista que ha sido descrito" (HI, 185; 6, 494). En cambio, en El hombre y el Estado, se decanta Maritain expresamente por la influencia de la Iglesia sobre la base de su poder moral. "Esos principios -dice- se aplicarían menos en función del poder social que de la inspiración vivificante de la Iglesia" $(\mathrm{HE}, 181 ; 9,670) . Y$ todavía más explícitamente:

La superior dignidad de la Iglesia tiende así en nuestros días a hallar sus vías de realización en el pleno ejercicio de su poder de inspiración superior, capaz de penetrarlo todo (HE, 182; 9, 671).

\section{Conclusión}

En suma, el primado de lo espiritual, que defiende Maritain, conforme a la idea directriz de un regnum Dei, debe, no obstante, ejercerse por modo de influencia y fermentación, y no de poder temporal o privilegio social alguno. Esto es, por otra parte, concorde con el mismo principio de la encarnación, que supone no sólo presencia de lo espiritual en lo temporal sino anonadamiento en la forma de esta presencia. Y la forma de este anonadamiento es precisamente el servicio humilde 
y leal a la sociedad. En lo que respecta al fondo humanista de que hemos partido, la reacuñación de la democracia en clave personalista conlleva ya una superación del doble error del liberalismo individualista y del comunitarismo socialista, o, por mejor decir, una rectificación de sus humanismos respectivos, integrándolos en el principio de la persona y librándolos así de su unilateralidad y exageración. Maritain insiste, con un énfasis, a mi juicio excesivo, en sus demonios particulares.

La condena del liberalismo teológico por la Iglesia jamás se revocará, porque el liberalismo teológico implicaba la falsa autonomía metafísica de la razón y la voluntad (HI,201; HE,201; 9, 694).

La verdad es que no entiendo lo del "liberalismo teológico", (salvo que se trate de la idea que algunos teólogos se hacen del liberalismo), sino del liberalismo a secas, que a Maritain se le antoja erróneo en su desmesura sobre la instancia de la autonomía del individuo. Me imagino que afirmaciones semejantes podrían hacerse desde una postura canónica de la lglesia, acerca del "socialismo teológico", o por mejor decir, de un socialismo ateo. Pero con semejantes condenas de tono tan rotundas y tajantes se corre el riesgo de echar a pique la propia empresa maritainiana de salvación del humanismo. Hay también una tradición de un sano liberalismo, no ayuno de sentido social, y de un socialismo humanista o democrático. Tanto en el concepto de autonomía, como respeto sagrado al fuero interno de la conciencia, como en el de solidaridad se encierran conquistas humanistas definitivas, como bien sabe Maritain. El cristianismo puede reconocerse en ellas, promoverlas activamente y fundamentarlas desde su concepción de la persona humana, pero sin aspirar al monopolio de las mismas ni pretender prevalencia alguna, ni teórica ni práctica, en el cuerpo social. Ha de estar en pie de igualdad con otras fuerzas ideológicas y comunidades de sentido y hacerse valer en la sociedad civil con su influencia moral y su testimonio de vida, pues lo que en verdad importa es que esta obra en común, (y sólo puede entender esta comunidad como concurrencia, no en competencia, sino en complementariedad de los diversos humanismos), logre en la praxis una política efectiva de las personas y no de los meros individuos ni de los grupos o colectivos sociales.

En un balance sumario, cabe decir que Maritain ha rectificado tanto el humanismo secularista como el trascendentalismo de la política hegemónica de la Iglesia católica en la ciudad secular. Su contribución fundamental ha sido renovar la comprensión filosófica y la praxis política del cristianismo, fundamentándolas en la categoría de persona, herencia única e insuperable de la tradición cristiana de pensamiento. Con ello, a su vez, ha establecido un nuevo planteamiento entre las relaciones de la religión y la democracia, que ha sido preludio, en buena parte, de nuestra forma actual de ver el problema. Hay, no obstante, un dejo nostálgico 
excesivamente trascendentalista en su planteamiento, propio de quien ha escrito La primacía de lo espiritual (Primauté du spirituel). A mi entender esta primacía ha de estar vigente en el fuero interno de la conciencia cristiana, pero sin pretensión de reconocimiento alguno en el orden político. La esfera estatal es tan autónoma en su género que está fundada exclusivamente en aquella ética civil, hoy compendiada en los derechos humanos, que pueden suscribir el sano corazón y la inteligencia ilustrada de cualquier hombre. La presencia pública del cristianismo es de pura inspiración y motivación moral. Esto no lo desarma a la hora de exponer su mensaje, con toda libertad e igual derecho a otras comunidades de sentido, en el seno de la sociedad civil, sino que más bien lo sitúa en el mismo plano de concurrencia con otras ideologías y comunidades religiosas, sin más valimiento que la fuerza regeneradora de su propio mensaje. Sólo un cristianismo así, desasistido de todo privilegio social, de todo apoyo político, puede ser fiel al anonadamiento de la encarnación. 